\title{
CONTROLE DE PRAGAS DO PESSEGUEIRO ATRAVÉS DO ENSACAMENTO DOS FRUTOS ${ }^{1}$
}

\author{
Control peach crop pests by fruits bagging
}

\author{
Luciano Rodrigues Coelho² ${ }^{2}$ Sarita Leonel ${ }^{3}$, Wilson Badiali Crocomo ${ }^{4}$, Adriana Mascarette Labinas $^{5}$
}

\begin{abstract}
RESUMO
Objetivou-se, no trabalho, buscar opções ao ensacamento de pêssegos, visando o controle eficiente das principais pragas do pessegueiro. Para isso, instalou-se um experimento em um pomar comercial de pêssego do cultivar Aurora 2, conduzido em sistema de vaso e espaçamento de $6 \times 4 \mathrm{~m}$. Os tratamentos foram os seguintes: T1 - Sacolas de TNT branco $\left(45 \mathrm{~g} / \mathrm{m}^{2}\right)$ fechado, T2 - Sacolas de TNT branco $\left(45 \mathrm{~g} / \mathrm{m}^{2}\right)$ aberto, T3 - Sacolas de TNT branco $\left(20 \mathrm{~g} / \mathrm{m}^{2}\right)$ fechado; T4 - Sacolas de TNT branco $\left(20 \mathrm{~g} / \mathrm{m}^{2}\right)$ aberto; T5 - Sacolas de polipropileno microperfurado transparente (furos de 1mm) fechado; T6 - Sacolas de polipropileno microperfurado transparente (furos de 1mm) aberto; T7 - Sacolas de polipropileno microperfurado transparente (furos de $2 \mathrm{~mm}$ ) fechado; T8 Sacolas de polipropileno microperfurado transparente (furos de $2 \mathrm{~mm}$ ) aberto; T9 - Sacolas de polietileno microperfurado leitoso (furos de 1mm) fechado; T10 - Sacolas de polietileno microperfurado leitoso (furos de 1mm) aberto; T11 - Sacolas de polietileno microperfurado leitoso (furos de $2 \mathrm{~mm}$ ) fechado; T12 - Sacolas de polietileno microperfurado leitoso (furos de 2mm) aberto; T13 Sacolas de papel impermeável fechado; T14 - Sacolas de papel impermeável aberto; T15 - Testemunha (sem ensacamento). De acordo com os resultados concluiu-se que todas as embalagens foram eficientes no controle de moscas-das frutas e pássaros, porém não para mariposa oriental. As sacolas com abertura no fundo podem ser utilizadas como opção ao ensacamento de pêssegos.
\end{abstract}

Termos para indexação: Prunus persica, sacolas, moscas-das-frutas, mariposa oriental.

\begin{abstract}
Aiming to look for new options of peach bagging in the control of peach insect pests, an experiment was carried out in a treeyear-old peach crop. The cultivar Aurora 2 was accomplished in vase system with $6 \mathrm{~m}$ among rows and $4 \mathrm{~m}$ among plants. The treatments were: T1 - white and closed TNT (tissue non-tissue) bag $\left(45 \mathrm{~g} / \mathrm{m}^{2}\right), \mathrm{T} 2$ - white and opened TNT bag $\left(45 \mathrm{~g} / \mathrm{m}^{2}\right)$, T3 - white and closed TNT bag $\left(20 \mathrm{~g} / \mathrm{m}^{2}\right)$, T4 - white and opened TNT bag $\left(20 \mathrm{~g} / \mathrm{m}^{2}\right)$, T5 - transparent polypropelene microperfurated and closed bag ( $1 \mathrm{~mm}$ of diameter), T6 - transparent polypropelene microperfurated and opened bag (1mm of diameter), T7 - transparent polypropelene microperfurated and closed bags ( $2 \mathrm{~mm}$ of diameter), T8 - transparent polypropelene microperfurated and opened bag ( $2 \mathrm{~mm}$ of diameter), T9 - milky microperfurated polyetilene and closed bag (1mm of diameter), T10 - milky microperfurated polyetilene and opened bag ( $1 \mathrm{~mm}$ of diameter), T11 - milky microperfurated polyetilene and closed bag ( $2 \mathrm{~mm}$ of diameter), T12 milky microperfurated polyetilene and opened bags ( $2 \mathrm{~mm}$ of diameter), T13 - closed and waterproof paper bag, T14 - opened and waterproof paper bag, T15 - check treatment (unbagging fruits). According to the results, it may be concluded that all bags are efficient to control fruit flies and birds, but not the oriental fruit moth. The opened bags may be used in peach bagging.
\end{abstract}

Index terms: Prunus persica, bags, fruit fly, oriental fruit moth.

(Recebido em 15 de maio de 2008 e aprovado em 20 de agosto de 2008)

\section{INTRODUÇÃO}

Os insetos-praga representam uma constante ameaça e um desafio ao produtor de pêssego, pois existem inúmeras espécies que, esporádica ou constantemente, causam perdas econômicas significativas. Além dessas perdas diretas, os prejuízos ambientais, principalmente em virtude do uso de inseticidas, devem ser considerados (SALLES, 2003).
Dentre as principais pragas que atacam a cultura do pessegueiro estão as moscas-das-frutas (Anastrepha fraterculus, A. obliqua, e Ceratitis capitata) e a mariposa oriental (Grapholita molesta) (GALLO et al., 2002). Embora o ensacamento dos frutos seja uma prática que demanda mão-de-obra, tornando difícil sua prática em grandes pomares, ele é um controle eficiente para moscas-das-frutas e pode auxiliar também no controle da mariposa oriental,

\footnotetext{
${ }^{1}$ Parte da dissertação de mestrado do primeiro autor apresentada à Faculdade de Ciências Agronômicas da UNESP/Botucatu, SP.

'Engenheiro Agrônomo, Mestre em Horticultura - Departamento de Ciências Agrárias - Laboratório de Entomologia - Universidade de Taubaté/UNITAU Estrada Doutor José Luis Cembraneli, 5000 - Itaim - 12081-010 - Taubaté, SP - luciano.coelho@unitau.br

${ }^{3}$ Engenheira Agrônoma, Doutora, Professora - Departamento de Produção Vegetal/DPV - Faculdade de Ciências Agronômicas/FCA - Universidade Estadual Paulista/UNESP - Rua José Barbosa de Barros, 1780 - Cx. P. 237 - 18610-307 - Botucatu, SP - sarinel@fca.unesp.br - Bolsitsa CNPq ${ }^{4}$ Engenheiro Agrônomo, Doutor, Professor Assistente - Departamento de Produção Vegetal/DPV - Faculdade de Ciências Agronômicas/FCA Universidade Estadual Paulista/UNESP - Rua José Barbosa de Barros, 1780 - Cx. P. 237 - 18610-307 - Botucatu, SP - crocomo@fca.unesp.br ${ }^{5}$ Engenheira Agrônoma, Doutora, Professora Assistente - Departamento de Ciências Agrárias - Universidade de Taubaté/UNITAU - Estrada Doutor José Luis Cembraneli, 5000 - Itaim - 12081-010 - Taubaté, SP - labinas@unitau.br
} 
sobretudo em pomares que objetivam a produção de frutos com menor uso de defensivos agrícolas.

Além do pessegueiro e nectarineira, o ensacamento é um método de controle cultural de pragas indicado na cultura da goiabeira, para o controle do gorgulho e das moscas-das-frutas (BARBOSA et al., 2001; SOUZA et al., 2003), em nespereira, para o controle de moscas-das-frutas, mariposa oriental e proteção dos raios solares (GALLO et al., 2002; OJIMA et al., 1999) e também em gravioleira, visando o controle da broca dos frutos, Cerconota anonella (BARROS SOBRINHO et al., 1998). Pode-se também melhorar a coloração e a aparência dos frutos, diminuir ou prevenir doenças, além de manter as características físico-químicas dos mesmos.

As sacolas comumente utilizadas no ensacamento de pêssegos são de papel manteiga ou encerada, apresentando coloração branca. Embora ofereçam proteção segura contra as moscas-das-frutas, deixam um pouco a desejar em relação ao controle da mariposa oriental, pois as mariposas podem ovipositar sobre as sacolas e as lagartas recém-eclodidas conseguem atravessá-las, caso ela entre em contato com o fruto, sem contar a baixa resistência desses materiais às intempéries, como ventos e chuvas de granizo.

Objetivou-se, no presente trabalho, avaliar outros materiais para o ensacamento dos pêssegos, inclusive sacolas com abertura no fundo, visando o controle eficiente das principais pragas do pessegueiro.

\section{MATERIALE MÉTODOS}

O trabalho foi realizado no Sítio Santa Maria, no município de São Luis do Paraitinga, SP (latitude

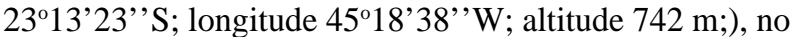
período de agosto a novembro de 2006, em um pomar comercial de pêssego da cultivar Aurora 2 , de três anos de idade, conduzido em sistema de vaso e espaçamento de 6 x 4 m. O clima da região, segundo a classificação de Köeppen, é do tipo Cwa: tropical de altitude, com inverno seco e chuvas de verão.

O delineamento experimental utilizado foi em blocos casualizados, onde cada planta foi considerada um bloco, utilizando-se 15 tratamentos, 8 repetições (blocos) e 10 frutos por parcela experimental (tratamento). As plantas utilizadas no experimento não receberam nenhum tratamento fitossanitário. Os tratamentos utilizados no experimento estão descritos na Tabela 1 .

As sacolas de papel impermeável, polipropileno transparente e polietileno leitoso foram obtidas diretamente nas lojas agropecuárias da região.

Nas sacolas de polipropileno e polietileno, os furos foram feitos de modo artesanal utilizando-se alfinetes entomológicos de 1 e $2 \mathrm{~mm}$ de diâmetro. Para as sacolas de TNT, comprou-se o tecido em tapeçarias, e confeccionouse de maneira artesanal também, costurando as extremidades. A sigla TNT significa tecido-não-tecido, sendo que existem várias cores desse material disponíveis no mercado, como vermelho, verde, amarelo, branco, e

Tabela 1 - Tipos de materiais e dimensões (largura x comprimento) utilizados no ensacamento de pêssego cv. Aurora 2. São Luis do Paraitinga-SP, 2006.

\begin{tabular}{clc}
\hline & \multicolumn{1}{c}{ Tratamentos } & Dimensões $(\mathrm{cm})$ \\
\hline T1 & Sacolas de TNT branco de 45 gramaturas por $\mathrm{m}^{2}\left(45 \mathrm{~g} / \mathrm{m}^{2}\right)$ fechado & $11,5 \times 15,0$ \\
T2 & Sacolas de TNT branco de 45 gramaturas por $\mathrm{m}^{2}\left(45 \mathrm{~g} / \mathrm{m}^{2}\right)$ aberto & $11,5 \times 15,0$ \\
T3 & Sacolas de TNT branco de 20 gramaturas por $\mathrm{m}^{2}\left(20 \mathrm{~g} / \mathrm{m}^{2}\right)$ fechado & $11,5 \times 15,0$ \\
T4 & Sacolas de TNT branco de 20 gramaturas por $\mathrm{m}^{2}\left(20 \mathrm{~g} / \mathrm{m}^{2}\right)$ aberto & $11,5 \times 15,0$ \\
T5 & Sacolas de polipropileno microperfurado transparente (furos de $1 \mathrm{~mm})$ fechado & $13,0 \times 20,0$ \\
T6 & Sacolas de polipropileno microperfurado transparente (furos de $1 \mathrm{~mm})$ aberto & $13,0 \times 20,0$ \\
T7 & Sacolas de polipropileno microperfurado transparente (furos de $2 \mathrm{~mm})$ fechado & $13,0 \times 20,0$ \\
T8 & Sacolas de polipropileno microperfurado transparente (furos de $2 \mathrm{~mm})$ aberto & $13,0 \times 20,0$ \\
T9 & Sacolas de polietileno microperfurado leitoso (furos de $1 \mathrm{~mm})$ fechado & $13,0 \times 15,0$ \\
T10 & Sacolas de polietileno microperfurado leitoso (furos de $1 \mathrm{~mm})$ aberto & $13,0 \times 15,0$ \\
T11 & Sacolas de polietileno microperfurado leitoso (furos de $2 \mathrm{~mm})$ fechado & $13,0 \times 15,0$ \\
T12 & Sacolas de polietileno microperfurado leitoso (furos de $2 \mathrm{~mm})$ aberto & $13,0 \times 15,0$ \\
T13 & Sacolas de papel impermeável fechado & $11,5 \times 15,0$ \\
T14 & Sacolas de papel impermeável aberto & $11,5 \times 15,0$ \\
T15 & Testemunha (sem ensacamento) & - \\
\hline
\end{tabular}

Ciênc. agrotec., Lavras, v. 32, n. 6, p. 1743-1747, nov./dez., 2008 
também várias gramaturas, ou seja, um TNT $20 \mathrm{~g} / \mathrm{m}^{2}$ é mais transparente que um de $45 \mathrm{~g} / \mathrm{m}^{2}$. Esse material é facilmente encontrado em lojas que vendem armarinhos em geral (alfinetes e linhas). Quanto ao papel impermeável, ele é muito parecido com o papel manteiga, mas não é o mesmo. Tanto o TNT quanto o papel impermeável resistem à chuva e são brancos.

O ensacamento foi realizado manualmente e logo após o raleio dos frutos, quando eles atingiram diâmetro entre 1,5 a $2 \mathrm{~cm}$, dando preferência aos frutos voltados para baixo (PEREIRA \& RASEIRA, 2003). As sacolas foram fixadas com auxílio de um arame fino preso no próprio galho.

A incidência de moscas-das-frutas e mariposa oriental foi determinada de maneira visual, após o despolpamento dos frutos, verificando-se a presença ou ausência de larvas e/ou lagartas no interior dos frutos. Para abelha arapuá e pássaros, os sintomas de ataque foram determinados apenas de maneira visual, sem realizar o despolpamento dos frutos.

O monitoramento da flutuação populacional foi realizado, simultaneamente, para os três insetos-praga. Para isso, utilizou-se uma armadilha feita com garrafa plástica do tipo Pet (2 litros), na qual se abriram quatro furos de 1 $\mathrm{cm}$ de diâmetro no terço superior e que foi colocada na linha das plantas escolhidas para a instalação do experimento, a uma altura de aproximadamente $1,60 \mathrm{~cm}$ do solo, na periferia da copa. $\mathrm{O}$ atrativo utilizado foi caldo-decana a $50 \%$. A cada 10 dias substituiu-se o atrativo e contouse o número de insetos nas armadilhas.

Os dados foram expressos em porcentagem e transformados em raiz de $(\mathrm{x}+0,5)$. Posteriormente, foram submetidos à análise de variância e as médias comparadas pelo teste de Tukey $(P=0,05)$.

\section{RESULTADOS E DISCUSSÃO}

Todos os tratamentos, inclusive as sacolas abertas no fundo, foram eficientes no controle das moscas-dasfrutas e pássaros (Tabela 2). Isso comprova que sacolas abertas, assim como já acontece comumente em produções de nespereira, nos quais se ensacam os cachos após o raleio dos frutos, com folhas duplas de jornal (OJIMA et al., 1999), também podem ser uma opção para o ensacamento de pêssegos. Já para os pássaros, embora neste trabalho os saquinhos tenham sido eficientes, deve-se ressaltar que,

Tabela 2 - Porcentagem de frutos de pêssego cv. Aurora 2 danificados por mariposa oriental, moscas-das-frutas, pássaros e abelha arapuá. São Luis do Paraitinga-SP, 2006.

\begin{tabular}{|c|c|c|c|c|c|}
\hline & \multirow[t]{2}{*}{ Tratamentos } & \multicolumn{4}{|c|}{ Frutos danificados $(\%)$} \\
\hline & & $\begin{array}{c}\text { Mariposa } \\
\text { oriental }\end{array}$ & $\begin{array}{l}\text { Moscas- } \\
\text { das-frutas }\end{array}$ & Pássaros & $\begin{array}{l}\text { Abelha } \\
\text { arapuá }\end{array}$ \\
\hline $\mathrm{T} 1$ & TNT $\left(45 \mathrm{~g} / \mathrm{m}^{2}\right)$ branco fechado & $12,79 \mathrm{a}$ & 0 & 0 & $0 \mathrm{c}$ \\
\hline $\mathrm{T} 2$ & TNT $\left(45 \mathrm{~g} / \mathrm{m}^{2}\right)$ branco aberto & 8,33 a & 0 & 0 & $0 \mathrm{c}$ \\
\hline $\mathrm{T} 3$ & TNT $\left(20 \mathrm{~g} / \mathrm{m}^{2}\right)$ branco fechado & $11,97 \mathrm{a}$ & 0 & 0 & $0 \mathrm{c}$ \\
\hline $\mathrm{T} 4$ & TNT $\left(20 \mathrm{~g} / \mathrm{m}^{2}\right)$ branco aberto & $3,86 \mathrm{a}$ & 0 & 0 & $10,87 \mathrm{bc}$ \\
\hline T5 & Polipropileno microperfurado transparente (furos de $1 \mathrm{~mm}$ ) fechado & 15,66 a & 0 & 0 & $0 \mathrm{c}$ \\
\hline T6 & Polipropileno microperfurado transparente (furos de $1 \mathrm{~mm}$ ) aberto & $14,27 \mathrm{a}$ & 0 & 0 & $4,06 \mathrm{bc}$ \\
\hline $\mathrm{T} 7$ & Polipropileno microperfurado transparente (furos de $2 \mathrm{~mm}$ ) fechado & 18,96 a & 0 & 0 & $0 \mathrm{c}$ \\
\hline $\mathrm{T} 8$ & Polipropileno microperfurado transparente (furos de $2 \mathrm{~mm}$ ) aberto & $17,49 \mathrm{a}$ & 0 & 0 & $2,08 \mathrm{bc}$ \\
\hline T9 & Polietileno microperfurado leitoso (furos de $1 \mathrm{~mm}$ ) fechado & 16,77 a & 0 & 0 & $0 \mathrm{c}$ \\
\hline $\mathrm{T} 10$ & Polietileno microperfurado leitoso (furos de $1 \mathrm{~mm}$ ) aberto & $10,86 \mathrm{a}$ & 0 & 0 & $16,30 \mathrm{~b}$ \\
\hline $\mathrm{T} 11$ & Polietileno microperfurado leitoso (furos de $2 \mathrm{~mm}$ ) fechado & $13,68 \mathrm{a}$ & 0 & 0 & $0 \mathrm{c}$ \\
\hline $\mathrm{T} 12$ & Polietileno microperfurado leitoso (furos de $2 \mathrm{~mm}$ ) aberto & $12,43 \mathrm{a}$ & 0 & 0 & $9,95 \mathrm{bc}$ \\
\hline $\mathrm{T} 13$ & Papel impermeável fechado & $13,34 \mathrm{a}$ & 0 & 0 & $0 \mathrm{c}$ \\
\hline T14 & Papel impermeável aberto & $7,50 \mathrm{a}$ & 0 & 0 & $7,50 \mathrm{bc}$ \\
\hline \multirow[t]{2}{*}{$\mathrm{T} 15$} & Sem ensacamento (testemunha) & $22,76 \mathrm{a}$ & 69,53 & 15,48 & $37,07 \mathrm{a}$ \\
\hline & C.V. $(\%)$ & 62,31 & - & - & 75,29 \\
\hline
\end{tabular}

Análise realizada sobre os dados transformados em raiz quadrada de $(x+0,5)$.

Médias seguidas pela mesma letra, nas colunas, não diferem entre si pelo teste de Tukey $(P=0,05)$. 
caso todos os frutos fossem ensacados, os resultados poderiam ser diferentes, uma vez que os pássaros vão sempre preferir aqueles frutos que estejam mais fáceis de serem atacados, como é o caso dos não ensacados. As sacolas abertas mostraram-se eficientes no controle de moscas-das-frutas e pássaros, além de permitirem a visibilidade dos frutos no seu interior, mesmo quando se utilizam materiais que são comuns na região, mas que não sejam transparentes.

Em relação à mariposa oriental, as sacolas, tanto abertas no fundo como fechadas, não foram eficientes, não diferindo estatisticamente da testemunha, sem ensacamento. No entanto, as sacolas abertas apresentaram valores sempre menores do que as fechadas. Os adultos da mariposa oriental ovipositam em qualquer parte da planta, e as lagartinhas recém-eclodidas caminham em direção aos frutos, entrando sempre pela região do pedúnculo. Caso as sacolas não estejam muito bem vedadas, essas lagartinhas podem entrar por uma pequena abertura e atacar frutos mesmo ensacados. Uma vez que as lagartinhas conseguem atingir os frutos ensacados, elas preferirão as sacolas fechadas, pois a variação de temperatura no seu interior é menor, formando um micro clima ideal para o seu desenvolvimento.

No que se refere à abelha arapuá, os melhores tratamentos foram sempre as sacolas fechadas, com exceção do tratamento T2 (Sacolas de TNT branco de 45 gramaturas por $\mathrm{m}^{2}\left(45 \mathrm{~g} / \mathrm{m}^{2}\right)$ aberto). As sacolas abertas, embora apresentando algum dano, diferiram da testemunha, sem ensacamento, a qual apresentou $37,07 \%$ de frutos atacados, mostrando que as sacolas, mesmo abertas dificultaram o acesso aos frutos por esses insetos.

A abelha arapuá não é considerada praga na cultura do pêssego, mas nesse experimento causou danos elevados. Esse inseto apresenta mandíbulas com as quais fazem pequenos furos nos frutos de pêssego, tornandoos impróprios para a comercialização e favorecendo a ocorrência de podridão parda. Isso demonstra que, na maioria das vezes, os insetos não são pragas, mas sim, assumem o papel de pragas agrícolas por encontrarem nas áreas agricultáveis, condições que os favoreçam num determinado instante (CROCOMO, 1990).

Observando a flutuação populacional dos insetospraga (Figura 1) percebe-se que a população de moscasdas-frutas sempre esteve elevada, sofrendo uma queda nas três últimas avaliações (26/10, 5/11 e 15/11). Esse fato ocorreu porque, além da armadilha utilizada para o monitoramento, existiam mais 40 armadilhas em todo o pomar, auxiliando no controle de pragas, contribuindo para

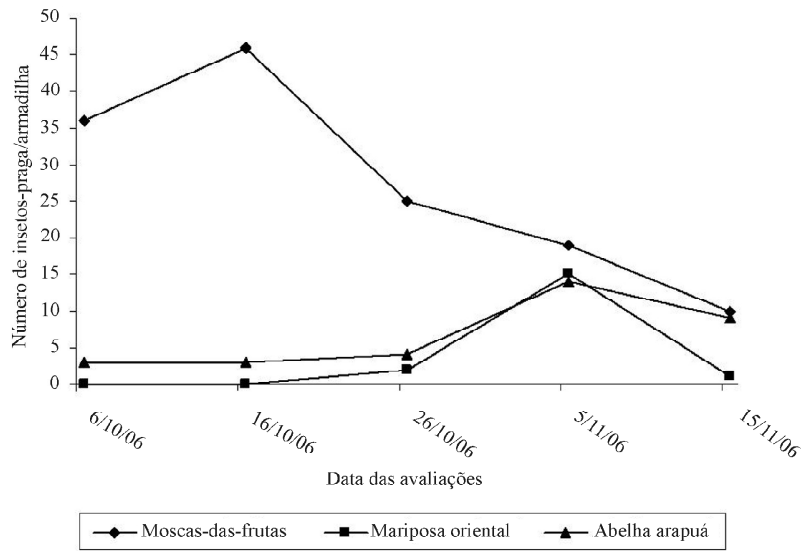

Figura 1 - Flutuação populacional de insetos-praga, no período de 26 de setembro a 15 de novembro de 2006, no pomar de pêssego cv. Aurora 2. São Luis do Paraitinga, SP.

a redução da população das moscas-das-frutas pela captura desses insetos.

O número de insetos capturados de mariposa oriental esteve baixo nas três primeiras avaliações ( $6 / 10$, 16/10 e 26/10), sofrendo uma elevação na $4^{\text {a }}$ avaliação (5/ 11), suficiente para atingir o nível de dano econômico, que é de 10 mariposas/armadilha/semana, mas baixando novamente na última avaliação. Esse tipo de armadilha não é considerado ideal para o monitoramento desse inseto, sendo a utilização de feromônios a mais indicada (SALLES, 2003). No entanto, essa armadilha costuma ser empregada pelos produtores devido à praticidade, pelo monitoramento simultâneo de duas pragas, e também pelo baixo custo.

A população da abelha arapuá se manteve constante nas primeiras avaliações $(6$ e 16/10) e teve um aumento nas três últimas (26/10, 5/11 e 15/11). Esse aumento é explicado devido à aproximação da época de colheita dos frutos, tornando-os mais atrativos para esse inseto, pela diminuição da firmeza, fato que acontece naturalmente pelo avanço do processo de amadurecimento.

\section{CONCLUSÕES}

O ensacamento de pêssegos com sacolas de TNT, polipropileno, polietileno e papel impermeável foram eficientes no controle de moscas-das frutas e pássaros, porém não foram eficientes no controle da mariposa oriental.

As sacolas com abertura no fundo podem também ser utilizadas no ensacamento de pêssegos. 


\section{REFERÊNCIAS BIBLIOGRÁFICAS}

BARBOSA, F. R.; NASCIMENTO, A. S.; OLIVEIRA, J. V.; ALENCAR, J. A.; HAQJI, F. N. P. Pragas. In: NASCIMENTO, A. S.; BARBOS, F. R.; HAJI, F. N. P.; ALENCAR, J. A.; OLIVEIRA, J. V.; LIMA, M. F.; LOPES, P. R. C.; SHARMA, R. D.; TAVARES, S. C. C. H.; MOREIRA, W. A. Goiaba: fitossanidade. Petrolina, PE: Embrapa SemiÁrido; Brasília, DF: Embrapa Informação Tecnológica, 2001. p. 29-53. (Frutas do Brasil, 18).

BARROS SOBRINHO, R.; OLIVEIRA, M. A. S.; WARUMBY, J.; MOURA, J. I. L. Pragas da gravioleira. In: BARROS SOBRINHO, R.; CARDOSO, J. E.; FREIRE, F. C. $O$. Pragas de fruteiras tropicais de importância agroindustrial. Brasília, DF: Embrapa-SPI; Fortaleza: Embrapa-CNPAT, 1998. p. 131-141.

CROCOMO, W. B. O que é o manejo de pragas. In: FORTI, L. C.; ZUCCHI, R. A.; SOUZA NETO, S.; BERTI FILHO, E.; SALLES, L. A. B.; PARRA, J. R. P.; ALVES, S. B.; VENDRAMIN, J. D.; BATISTA, G. C.; GODOY, J. R.; CHIAVEGATO, L. G.; JAEHN, A.; BLEICHER, E.; PANIZZI, A. R.; CARVALHO, R. P. L. Manejo integrado de pragas. Botucatu, SP: Unesp; São Paulo: CETESB, 1990. p. 9-34.
GALLO, D.; NAKANO, O.; SILVEIRA NETO, S.; CARVALHO, R. P. L.; BAPTISTA, G. C.; BERTI FILHO, E.; PARRA, J. R. P.; ZUCCHI, R. A.; ALVES, S. B.; VENDRAMIN, J. D.; MARCHINI, L. C.; LOPES, J. R. S.; OMOTO, C. Entomologia agrícola. Piracicaba: FEALQ, 2002. v. 10,920 p.

OJIMA, M.; CAMPO-DALL ORTO, F. A.; BARBOSA, W.; MARTINS, F. P.; SANTOS, R. R. dos. Cultura da nespereira. Campinas: IAC, 1999. 36 p. (Boletim técnico, 185).

PEREIRA, J. F. M.; RASEIRA, A. Raleio. In: RASEIRA, M. C. B.; CENTELHAS-QUEZADA, A. Pêssego: produção. Brasília, DF: Embrapa Clima Temperado, 2003. p. 96-100.

SALLES, L. A. B. Principais pragas e seu controle. In: RASEIRA, M. C. B.; CENTELHAS-QUEZADA, A. Pêssego: produção. Brasília, DF: Embrapa Clima Temperado, 2003. p. 123-135.

SOUZA, J. C.; HAGA, A.; SOUZA, M. A. Pragas da goiabeira. Belo Horizonte: Epamig, 2003. 60 p. (Boletim técnico, 71). 